\title{
A New Probabilistic Problem-Solving Paradigm: A Conceptual Critical Reflection
}

\author{
Chris William Callaghan
}

\author{
Knowledge and Information Economics/Human Resources Research Agency (KIEHRA), School of Economic and Business
}

Sciences, University of the Witwatersrand, Johannesburg

Email: chris.callaghan@wits.ac.za

\section{Doi:10.5901/mjss.2014.v5n23p2070}

\section{Abstract}

For Coase, organisations exist because they manage resources more efficiently than markets can. In contrast, for Grant, organisations exist because they are more efficient at integrating knowledge. Therefore, according to Grant, certain types of knowledge, such as tacit knowledge, cannot be transferred efficiently; problem solving therefore needs to be devolved to the level of the individual. Similarly, the work of Hayek and von Hippel suggests that knowledge is 'sticky' and cannot easily be transferred. In this paper the argument is made that a second generation of problem solving research and development management systems need to be developed; as a global system of distributed problem solving, in order to be able to deal with specific types of problems, termed 'catastrophic events', that may arise.

Keywords: open innovation; crowdsourcing; medical research; cure; problem solving; second generation innovation; R\&D

\section{Introduction}

For Coase (1937), organisations exist because they manage resources more efficiently than markets can. In contrast, for Grant (1996), organisations exist because they are more efficient at integrating knowledge. Therefore, following Grant (1996), certain types of knowledge, such as tacit knowledge, cannot be transferred efficiently; problem solving therefore needs to be devolved to the level of the individual. In this paper it is argued that a certain type of devolution of problem solving is needed to solve certain types of problems, which for the purposes of this paper are termed 'catastrophic events'. For problems such as, for example, disease pandemics that provide data only after their onset, a second generation of research and development management problem solving based on distributed problem solving, may be required. However, if an organisation exists primarily to integrate knowledge, then it requires common knowledge (Grant, 1996), or a common language. For Grant (1996), the primary role of a firm is the integration of the specialised knowledge of individuals in order to provide outcomes such as goods and services; the primary task of management is to provide the coordination required of this process of knowledge integration. It is argued here that the common language of multidisciplinary problem solving needs to be management theory, and more specifically innovation management theory. In this paper, an example of a specific form of problem is used as a heuristic. This is done in order to make the argument that the proactive development of a global system of $R \& D$ management in the form of distributed problem solving is necessary in order to address 'catastrophic'-type problems which may occur in future.

Disaster management already applies management theory in order to manage the potentially catastrophic consequences of disasters. One form of disaster, or catastrophic event, can take the form of a bioevent. The bioevent is used as an ongoing example in this paper. Bioevents "are defined as large-scale disasters secondary to biological agents that either are naturally occurring (e.g., severe acute respiratory syndrome [SARS], influenza A, potential h5N1 outbreak) or deliberate (e.g., smallpox, inhalational plague, anthrax) in nature" (Burkle, 2006:1118). Bioevents are a special case of disaster which captures the essence of catastrophic events well. Communicable "disease is likely to be silent, odourless, invisible and undetectable for several days or weeks" (Burkle, 2006:1118). The 1918 influenza pandemic was responsible for the deaths of between 20 and 40 million people globally (Billings, 1997). The spread of this pandemic was enabled by global trade routes and shipping lines (Billings, 1997). Similar pandemics are evident from an examination of human history; the Bubonic Plague of 1347 is another example (Billings, 1997). Micro-organisms pose a current threat in the form of pandemics in a context of airline travel that links the globe (Maher, 2013). This paper argues that the development of a new paradigm of R\&D management systems is necessary to address such potential catastrophic problems; and specifically that a 'second-generation' model of R\&D based on a probabilistic perspective of knowledge management is necessary. It is therefore argued that the 'first-generation' systems of research (which by definition do not utilise distributed R\&D systems) are fundamentally antithetical to the requirements R\&D management where a disaster, 
or catastrophic event, has already occurred.

\section{The Objective of the Paper}

The objective of this paper is to provide a conceptual critical reflection on the current role of innovation management as the academic field tasked with integrating knowledge to address emerging societal problems or challenges. The thesis statement of this paper is that the management of these types of problems, or catastrophic events, requires a 'next generation' of problem solving methodologies of R\&D, or distributed R\&D management. The generational metaphor, associated as it is with technological innovation, is applied to make this argument. Next generation, or second generation methodologies of distributed R\&D management, are considered here to be those that incorporate a probabilistic mechanism in their approach to problem solving. This paper attempts to contribute to the innovation management literature in several ways. First, it adds to the ongoing discussions of the threats posed by risky events, and the unique role of innovation management theory and practice in providing leadership. Second, insights are linked to economic theory that justifies the probabilistic approach to innovation management applied to problem solving. Against this backdrop, evidence in the form of prior applications of probabilistic R\&D management are introduced, with specific reference to a form known as 'crowdsourcing'. Lastly, the paper contributes to conversations on how innovation should be organised in different contexts using distributed R\&D management principles. The notion of 'probabilistic' R\&D is now introduced.

\section{A Probabilistic Mechanism of R\&D}

A probabilistic mechanism exists when exponentially increasing inputs to a problem are enabled. In terms of a perhaps simplistic example; this exists where significantly more people are able to contribute inputs into a problem. For instance, one person solving the problem increases to two, to four, to sixteen, to sixty-four, to four thousand and ninety-six, and so on. An example of this is the use of thousands of scientists in related fields that together focus on one particular problem at a point in time with the goal of solving it. An example of a catastrophic event in the form of a bioevent is now used to illustrate the principle behind the operation of distributed R\&D management systems. The underlying probabilistic mechanism of this form of distributed learning might be taken to mirror the exponential dynamics associated with bioevents. In the case of a bioevent, microorganisms do not seem to be constrained by the social or technical structures that may constrain the time and resources dimensions of human projects. Microorganisms seem to be able to spread to different people in an exponential way; one person can infect two; two can infect four; four can infect sixteen and so on (another perhaps simplistic example). This is perhaps just one example of the way microorganisms seem to utilise probabilistic mechanisms. The underlying principle at work here is that in the face of such an adversary, a mechanism of human learning needs to be able to use probabilistic principles in order to address such a threat; particularly in instances where data on the threat might only be available after an outbreak. It is argued that a distributed R\&D management methodology that can utilise such a probabilistic mechanism already exists in the form of 'crowdsourcing'.

\section{An example of the Challenge}

Currently, a new corona virus has emerged, which has been identified as a "threat to the entire world" by the World Health Organisation (WHO) (Zap, 2013:internet). No vaccine for this corona virus, termed the Middle East respiratory system coronavirus, or MERS-CoV, currently exists (Zap, 2013). Saudi Arabia has reported that the development of diagnostic tests for the Novel Corona Virus (NCoV) (which may or may not be another manifestation of MERS-CoV)have been held up by patent rights issues (these rights are held by commercial companies) (BBC, 2013). This is not the only pandemic threat to the world's population. In 2003, Severe Acute Respiratory Syndrome (SARS) was responsible for about 770 deaths (BBC, 2013). A strain of tuberculosis has evolved that is now resistant to all known drugs; it is incurable (Maher, 2013). Identified globally, it is starting to emerge in Mumbai and other densely populated cities in developing countries (Mahr, 2013). It is feared that this strain might have the potential to cause an untreatable global outbreak; airline travel connects the globe and tuberculosis transmission is primarily airborne (Maher, 2013). Further, Bacteria are increasingly resistant to antibiotics, and strains of 'superbugs' are emerging (Halifax, 2013).

Too little research and development (R\&D) is spent on developing new antibiotics because of the profitability models of commercial pharmaceutical companies (Halifax, 2013). Fears exist; that a return to a pre-antibiotic era is increasingly possible (Halifax, 2013). This threat has also been termed an emerging 'perfect storm' due to the importance of antibiotics in supporting much of what is done in medicine, from surgery to the management of secondary infections 
(Halifax, 2013). It is against this backdrop that it is argued that a probabilistic knowledge management model of R\&D management is required. Importantly, such a model needs to address the problems associated with a potential global pandemic where no prior data is available; where data is only available after the event is in motion. In other words, such a model would require the time dimension (Doloi, 2011) of an R\&D project to be 'crashed' or minimised; almost entirely. Typical constraints to project management outcomes (Doloi, 2011) make conventional project management methodology difficult to use to manage R\&D under bio-events of pandemic proportions. It is also argued that bio event resource management systems, based on policies that guide the supply of resources in disasters (Amin, Dam, Nicola, Salama \& Yassine, 2006), should incorporate the use of such second generation R\&D systems as a part of the planning for such events. Methodologies exist for bioevent management, such as triage systems (an example is the susceptible-exposedinfectious-removed-vaccinated (SEIRV) model) (Amin et al., 2006), but what does not seem to be incorporated into these preparatory systems are second generation R\&D management systems set up prior to these events.

\section{External Knowledge and the Need for Second Generation R\&D Systems}

"No matter who you are, most of the smartest people work for someone else"; this is Joy's Law, named for Bill Joy, the co-founder of Sun Microsystems (Lakhani \& Panetta, 2007:97). Joy's law relates to the primary knowledge management constraints faced by organisations; the fact that knowledge needed for R\&D typically exists outside the boundaries of any one particular organization (Lakhani \& Panetta, 2007). According to Lakhani and Panetta (2007:97), the causal explanation of Joy's Law is provided in the seminal work of economists Friedrich Hayek and Erik von Hippel on the distributed and sticky nature of knowledge and innovation. Hayek, in 1945, arguing for the importance of the market economy, emphasized that at the macro level knowledge is unevenly distributed in society, and that centralized models for economic planning and coordination are prone to failure due to an inability to aggregate this distributed knowledge. Thirty years later, micro-level studies by von Hippel began to suggest that in many industries users were the originators of most novel innovations. User's dominant role in originating innovations reflects the fact that knowledge is not only distributed but also "sticky", that is, relatively difficult and extremely costly to move between locations, thus shifting the location of innovation to where it is the stickiest.

It is argued that this 'stickiness' of knowledge renders non-probabilistic, or first generation, systems of R\&D unable to address the knowledge problems associated with certain forms of catastrophic events. For Lakhani and Panetta (2007:97), Joy's Law predicts challenges for R\&D that are "exacerbated by the explosion of knowledge in most scientific and technological fields". For example, according to the US National Library of Medicine (Medline), academic papers in life sciences increased about six and a half times over the period 1995 to 2005, from 105000 to 686000 papers (Lakhani \& Panetta, 2007). Closed models of proprietary innovation cannot competitively deliver R\&D outcomes without access to knowledge that exists outside the organisation (Lakhani \& Panetta, 2007).

An alternative model for organising innovation exists that transcends the problem of the 'stickyness of knowledge'; distributed systems of problem solving (Lakhani \& Panetta, 2007). The success of Linux and other open source software (OSS) systems has provided evidence of the success of distributed systems of problem solving, or distributed knowledge management systems; a proof of concept (Lakhani \& Panetta, 2007). It is argued that distributed systems of problem solving represent probabilistic systems of problem solving and are akin to being a 'second generation' of innovation, and more specifically R\&D problem solving by virtue of their differences from 'first generation' innovation, or R\&D problem solving. The terms probabilistic and distributed systems of problem solving are considered synonymous.

OSS communities are able to download source code and then develop it for their own needs with the modified source code typically returned to the Internet for others to develop further; discussion forums and collaborative work also arise from this process (Lakhani \& Panetta, 2007). Lakhani and Panetta (2007:100) quote Linus Torvalds, the founder of Linux, expressing the nature of this system as follows:

-free availability and_crosspollination_through sharing of 'source code', although biologists call it DNA. - a rather unforgiving user environment, that happily replaces bad versions of us with better working versions and thus culls the herd (biologists often call this 'survival of the fittest') - massive undirected parallel development ('trial and error')... Too strong a vision can kill you- you'll walk right over the edge firm in the knowledge of the path in front of you...l'd much rather have 'brownian motion', where a lot of microscopic directed improvements end up pushing the system slowly in a direction that none of the individual developers really had the vision to see on their own...And I'm a strong believer that in order for this to work_well_, you have to have a development group that is fairly strange and random.

The analogies are clear; references to the random, or probabilistic process of knowledge creation, and the biological metaphor of the evolution of DNA. It is argued that in the face of threats from certain catastrophic events, such as microorganisms that literally represent the evolution of DNA, a probabilistic mechanism of problem solving might be 
uniquely suited to addressing these threats.

At the heart of the efficiency and effectiveness of a second generation R\&D methodology is its promise of problem solving that requires significantly fewer resources. One of the puzzling aspects of open source software development is why information providers are willing to perform these tasks without remuneration (Lakhani \& von Hippel, 2003). Open source software has developed from Richard Stallman's "free software" movement and the Free Software Foundation (FSF) that sought to offer all users the "rights to use, modify and redistribute the programs code or any program derived from it but only if the distribution terms are unchanged" (Lakhani \& von Hippel, 2003:925). Open source contributors have been found to primarily be motivated by intrinsic motivation, particularly in terms of enjoyment, creativity, user need, intellectual stimulation and learning (Lakhani \& Wolf, 2003).

For Coase (1937), firms exist because in specialised exchange economies it is less costly in some cases for an organisation to co-ordinate exchange transactions than to let the market do it. The essential question, for Coase (1937:25) was "why one integrating force (the entrepreneur) should be substituted for another integrating force (the price mechanism). Applying open source innovation to the R\&D process is akin to changing the cost structure dynamics of the R\&D system. Using a distributed knowledge system can address both the problem with the stickyness of knowledge and the problem of cost in the integration of knowledge and its application to the solving of problems.

The existing processes of knowledge management R\&D, to the extent that they do not apply distributed systems of problem solving, might be considered to represent a 'first generation' set of practices that have been shaped by historical context, or first generation innovation.

The evolution of different forms of micro-organisms is reflected in the emergence, or evolution, of strains of bacteria and viruses; a form of adaptive behaviour, which for the purpose of this paper is loosely considered to represent 'learning'. The medicines that are used to hold the threat posed by these micro-organisms at bay are, necessarily, the outcome of a process of R\&D, which can also be considered to be a form of learning. If viewed from this perspective, these two forms of learning can be considered to reflect a 'race' for survival. If the 'learning' of micro-organisms is able to outstrip the 'learning' of human R\&D systems, the consequences could be catastrophic. It is acknowledged that the forms of R\&D that are termed 'second generation' and 'probabilistic R\&D' already exist in the form of distributed R\&D management systems. It is argued that the primary contribution this paper makes is in highlighting the importance of an immediate and more concerted and proactive application of this form of R\&D management to catastrophic problems, an example of which is disease research.

In order to support this argument, the notion that micro-organisms can, and do, 'learn' requires elaboration. According to Eshel (2009:78):

Under natural growth conditions bacteria live in complex hierarchical communities. To conduct complex cooperative behaviors, bacteria utilize sophisticated communication to the extent that their chemical language includes semantic and even pragmatic aspects. I describe how complex colony forms (patterns) emerge through the communication-based interplay between individual bacteria and the colony. Individual cells assume newly co-generated traits and abilities that are not prestored in the genetic information of the cells, that is, not all the information required for efficient responses to all environmental conditions is stored. To solve newly encountered problems, they assess the problem via collective sensing, recall stored information of past experience, and then execute distributed information processing of the $10^{9}$ or $10^{12}$ bacteria in the colony- transforming the colony into a "super-brain".

A detailed consideration of the more specific mechanisms through which micro-organisms adapt is beyond the scope and focus of this paper. Eshel's (2009) research is used here simply to make the point that micro-organisms are able to adapt, and that their ability to overcome human defences to pandemics can perhaps be seen as analogous to our ability to adapt and to hold these threats at bay; or overcome our challenges. First generation R\&D faces a myriad of challenges that constrain both its ability to provide problem solving in real time and to provide solutions to problems in maximally resource-constrained contexts.

Research in a conventional sense might be considered to occur iteratively, and in the form of an archipelago of knowledge, where the development of knowledge can be inefficiently duplicated and knowledge can be 'lost' to other researchers and practitioners. Oftentimes, academic research does not reach practitioners, and it ends up unused; the "Death Valley" phenomenon (Koyayashi, Nakamori \& Wierzbicki, 2007). First generation innovation faces a host of constraints (Callaghan, 2014a), and academic research can be constrained by values systems (Callaghan, 2014b). Differences in interests and values between different fields exist, which are even reflected in the interests and values of students (Coldwell \& Callaghan, 2013). For conventional knowledge creation, a first generation process of knowledge creation might indeed be superior to more focused applications of second generation or distributed knowledge management systems. The focus of this paper is on a certain type of problem, an example of which are disasters that only produce data once they have unfolded. 
No evidence seems to be present in the literature to suggest that second generation methodologies of innovation should supplant first generation methods of research. Second generation methodologies are complementary to first generation methods of innovation. In private innovation, information needs to be kept secret, and closed models of innovation have their place.

\section{The Case for the Development of a Distributed Knowledge Management System to Address Potential Catastrophic Events}

It is argued that in order to address the types of problems already introduced above, termed catastrophic events, a methodology needs to be set up, and tested, prior to such an event. A second generation R\&D management system needs to solve problems when hours lost to the process can result in the increased (perhaps exponentially increased) loss of human life. It needs to solve problems in real time and in a context where resources are not necessarily available, or are effectively unavailable. Two arguments are therefore presented in this paper: that a probabilistic model (a second generation) methodology of $R \& D$ can most effectively address a situation where a catastrophic event has occurred and no prior data about it is available. Similarly: that a pre-developed and extensively pre-tested system of R\&D management that applies a second-generation methodology of R\&D might better be able to address the threat of a catastrophic event. According to the literature, no extensive system exists at the present moment.

Biosurveillance systems do exist (Collmann \& Robinson, 2011). However, no system has been put into place on a global scale that is based on the principles of second generation R\&D management methodology. It is argued that this needs to be done immediately.

Keeping with the examples of bioevents as a form of catastrophic event used across this paper, the potential of a form of distributed knowledge management, termed crowdsourcing, to address these problems is now discussed further. Biosurveillance in the case of bioevents can be associated with ethical issues (Collmann \& Robinson, 2011). In response to these, doctrines have been crafted to handle such data according to fair information practices, and these have been developed by international consensus (Collman \& Robinson, 2011). One dimension of these biosurveillance systems is their need to access proprietary material, or copyrighted materials; which may have to be purchased (Collman \& Robinson, 2011). It is recommended that second generation R\&D targeted at the management of post-event bioevent pandemics should be developed to have access to such biosurveillance systems; that these linkages are organised and set up prior to such potential events. It is argued that it is the role and the responsibility of R\&D Management as a field to theorise and provide research to support practitioners from different fields in their endeavours related to the management of catastrophic events.

\section{The Scope of Management as a 'Problem Solving' Discipline in Service to Other Disciplines: Crowdsourcing as Part of Its Methodological Toolbox}

The application of management theory to research and problem solving makes R\&D Management as a discipline uniquely suited to solving interdisciplinary problems. Problem solving has transcended the realm prescriptions of the boundaries of professionalism (Bradham, 2008).

Crowdsourcing can provide solutions "superior in quality and quantity" than those of traditional forms of businesses (Bradham, 2008:79). For Bradham (2008:79):

The crowd solves the problems that stump corporate scientific researchers. The crowd outperforms in-house geophysicists at mining companies. The crowd designs a handful of original t-shirts every week which always sell out of stock. The crowd produces memorable commercials and fresh stock photography on a par with professional firms. And the crowd outperforms industry faster and cheaper than even the top minds in the fields.

The Internet has provided a platform that enables the use of crowdsourcing (Bradham, 2008). Crowdsourcing is fundamentally different from open-source production according to Bradham (2008). Both crowdsourcing and open source production are considered here to be distributed systems of R\&D Management, which have the potential to be developed into formal research methodologies within the ambit of the management discipline. They are not considered to be mutually exclusive, but to overlap and to complementary. Open source production refers to "allowing access to the essential elements of a product (such as a source code for software) to anyone for the purpose of collaborative improvement to the existing product, with the continued transparency and free distribution of the product" (Bradham, 2008:81).

The philosophy behind open source production is "transparency and access in the design stage and the ability to develop a product that is increasingly better, developed collectively and democratically"; while using a development 
process that outperforms other processes that are constrained by restrictive traditional intellectual property law (Bradham, 2008:82). Products such as the Mozilla Firefox web browser and the Linux operating system are examples of open source production (Bradham, 2008). Social capital has, in some cases, become the reward for contribution to this form of production, rather than monetary payment (Bradham, 2008). It is therefore to some extent robust to the resource constraints faced by first generation knowledge management systems.

Distributed innovation systems are associated with a phenomenon that cannot be explained by "the common view of "homo economicus", of purely self-interested participants" (Lakhani \& Panetta, 2007:103). Intellectual challenge, enjoyment, creativity, and norms have also been associated with OSS participation; participators are socialised to participate to the advantage of the group (Lakhani \& Panetta, 2007). A sense of belonging is also a feature of these systems (Lakhani \& Panetta, 2007).

One important type of catastrophic events is health related. Current health research trends have increasingly embraced crowdsourcing (Swan, 2012). Three forms of health-research crowdsourcing have emerged: (i) citizen science, or "non-professionally trained individuals conducting science-related activities"; (ii) crowdsourcing focused on the "use of web-based technologies to recruit project participants", and (iii) "medicine 2.0/health 2.0 (active participation of individuals in their health care particularly using web 2.0 technologies)" (Swan, 2012: 46). These are a natural offshoot of the development of health social networks, or online health interest communities (Swan, 2012). These developments have been characterised as a trend toward 'participatory health' (Swan, 2012). Researcher-organised crowdsourced research studies have resulted in publications in the field of disease research, drug response and genetic association (Swan, 2012). Underpinned by increasing internet and social network usage, these changes can lead to a "next generation understanding of disease and drug response" (Swan, 2012: 46). Importantly, having more people involved in crowdsourcing processes is creating new potentialities; the advent of "near-immediate speed at which medical findings might be tested and applied" (Swan, 2012: 46). It is this speed that is helpful in catastrophic contexts were data is only available after the onset of the event.

Social networks also provide 'early-warning' systems for disease, or bio-surveillance (Collier, Son \& Nguyen, 2011). Twitter responses, for example, have been used to track influenza protective behaviour categories and selfreported diagnoses in the USA (2009-2010) (Collier et al., 2011). The high levels of correlation between pre-diagnostic social media data and disease case data suggest that social media have the potential to provide "low cost sensor networks" for bio-surveillance (Collier et al., 2011). For Collier et al. (2011), programmes such as Google trends, which collect data about user's search queries, offer new opportunities for bio-surveillance. These features might be useful in the management of catastrophic events.

Crowdsourcing has driven a change in the underlying economics of knowledge supply products; those that used to be scarce can now be delivered (Howe, 2006). According to Howe (2006:1), in the same way that "distributed computing projects like UC Berkeley's distributed labour networks have tapped the unused processing power of millions of individual computers, so distributed labour networks are using the Internet to exploit the spare processing power of millions of human brains". The success of the open source software movement in rivalling the programming expertise of Microsoft and Sun Microsystems is further evidence of this concept (Howe, 2006). Similarly, the success of Wikipedia as an 'opensource' encyclopaedia and the successes of eBay and MySpace also provide support for the crowdsourcing model (Howe, 2006).

Industry changes have also occurred due to the rising influence of crowdsourcing (Howe, 2006). Cost barriers between amateurs and professionals are being eroded (Howe, 2006). "Hobbyists, part-timers, and dabblers suddenly have a market for their efforts, as smart companies in industries as disparate as pharmaceuticals and television discover ways to tap the latent talent of the crowd" (Howe, 2006:2). However, issues relating to the quality of inputs from crowdsourcing have arisen (Howe, 2006). Crowdsourcing as a form of data collection requires improvements, and has in some cases not been found to produce data comparable to that in the current medical literature; yet it shows future promise (Armstrong, Harskamp, Cheeney, Wu \& Schupp, 2012). Crowdsourcing inputs include those in the form of data and in the form of applied problem solving provided by participants.

Over time, it is possible that the quality of crowdsourced inputs will improve (Howe, 2006). Consumer behaviour can provide this impetus; in the US $57 \%$ of 12 to 17 year olds online are found to have posted some kind of content onto the Web (Howe, 2006). This trend is not limited to entertainment. Over 90000 individuals form a crowdsourced network of problem solvers undertaken research and development (R\&D) on a site called InnoCentive (Howe, 2006). InnoCentive was launched in 2001 by pharmaceutical company Eli Lilly (Howe, 2006). InnoCentive was developed by Alph Bingham, of Eli Lilly, who argued that until then "scientific problems were typically assigned to a single scientist or a small team possibly either not at the top in the problem domain or unaware of alternative approaches" (Lakhani \& Panetta, 2007:102). The iterative islands of progress might be taken to represent an 'archipelago' model of R\&D. 
Using InnoCentive, firms can pose problems and can offer cash prizes for the development of appropriate solutions and firms and contributors remain anonymous to each other (Lakhani \& Panetta, 2007). InnoCentive is effectively a knowledge broker; solutions and the intellectual property rights associated with the solution are traded for prize money (Lakhani \& Panetta, 2007). According to Coase's (1937) principle, an organisation form is typically needed when market exchange relationships are not efficient and cost more than it costs to organise relationships within an organisation; in the case of InnoCentive, less organizing is necessary, as the market provides a more efficient mechanism. This has resource implications because organisational boundaries are less of a constraint to the integration of knowledge around problems. Nonetheless, companies can also extend their knowledge management systems beyond their organisational boundaries to solve problems.

Boeing, DuPont and Proctor \& Gamble also post scientific problems onto this site (Howe, 2006). Individuals, termed 'solvers' are paid from $\$ 10000$ to $\$ 100000$ per solution; they also pay the site a fee to take part (Howe, 2006). The InnoCentive solver network includes over 12000 scientists that are based all over the globe (Lakhani \& Panetta, 2007). According to InnoCentive, over $30 \%$ of the problems posted on the site have been solved (Howe, 2006). The diversity of skills of contributors differentiates this process from traditional R\&D (Howe, 2006). Hobbyists dominate, and, surprisingly, research indicates that the chances of a problem being solved are higher in fields in which solvers have no formal knowledge (Howe, 2006). The broader the range of information, knowledge and experience involved the higher the chances of success in crowdsourced R\&D (Howe, 2006). One individual received $\$ 25000$ for an idea for how to inject fluoride powder into a toothpaste tube; this solution was considered to be relatively less expensive for the firm than it would have been to have in-house R\&D staff produce the same solution (Howe, 2006). In a context of rising costs of corporate R\&D, crowdsourcing offers options to corporates (Howe, 2006).

The rewards of embracing crowdsourced R\&D management systems are therefore clearly evident. An example is a top corporate company that now has 9000 people on its R\&D staff and up to 1.5 million researchers working through external networks (Howe, 2006). Through this shift to external networks, R\&D productivity has risen by $60 \%$ and the company's stock is at a five year high (Howe, 2006). The new cost models of crowdsourced content have also produced new television business models for 'repackaged' Internet video content obtained from crowdsource contributors (Howe, 2006). User-generated content is on the rise in television media (Howe, 2006). Having considered the potential of crowdsourcing as a second generation R\&D management methodology across different fields, the specific application of this methodology to health related disasters as a form of catastrophic event, and medical R\&D in general, is now considered.

\section{Second Generation R\&D in Medicine}

In the medical research context, dissatisfaction with the progress of first-generation R\&D has led to citizen-inspired change (Saparito, 2013). The current paradigm of medical research might not be suited to addressing the research challenges associated with catastrophic events in the form of medical disasters. Team-based and cross-disciplinary approaches to medical research have shown increasing promise (Saparito, 2013).

One area in which such progress is being made is in cancer research; one in every two men and one in every three women are expected to develop some form of cancer over their lifetimes (Saparito, 2013). Organisations such as Stand Up to Cancer have been started by entertainment industry figures who were unhappy about the way medical research is typically conducted; by the "narrow focused investigator... one small grant at a time" (Saparito, 2013:22). The notion of 'islands' of research funded iteratively bring to mind the archipelago analogy as a description of first generation R\&D. Medical research has typically been conducted in silos, yet the interventions of well known entertainment personalities is working to "transform the way an entire medical ecosystem operates" (Saparito, 2013:22). A new model of medical research has emerged based on approaching cancer research in the same way "you make a movie: bring the best and most talented people together, fund them generously, oversee their progress rigorously and shoot for big payoffs- on a tight schedule" (Saparito, 2013:22). This model, termed the 'dream team' model, is based on the use of teams, in one case comprising of about thirty people spanning about five institutions (Saparito, 2013). This model seems to reflect the need to integrate data and the knowledge of individuals that transcend organisational boundaries. This model might represent a step towards second-generation R\&D. It, however, is taken to still represent first-generation $R \& D$ in that the distributed component of problem solving is limited. First-generation $R \& D$ is not considered here to be antithetical to second generation R\&D; they can build on each other; the classification from first to second generation R\&D can be conceptualised as a continuum.

As more data and knowledge is recognised outside of research networks, these networks may ultimately expand to take advantage of this. The 'dream team' research model has also been enabled by a significant increase in the 
availability of genomic data; and the effectiveness of the team-based (termed 'dream teams') model of R\&D (Saparito, 2013). An important aspect of this model is that it holds patient outcomes as its primary objective (Saparito, 2013). As much as these developments seem to reflect the influence of citizen-driven change, this model is still considered to represent first-generation R\&D; it is not probabilistic in the distribution of its input networks. It therefore does not offer a system that can address the example posed in this paper; the threat of a catastrophic event such as a global pandemic. The ineffectiveness of first-generation research in terms of rapidly improving patient outcomes seems to be acknowledged, in a context of diminishing resources. For Saparito (2013:24):

Despite...urgency, shifting to a team model will not happen overnight, in part because the sociology of medical research isn't, in fact, very social. Historically, the principal investigator wins grant money for a proposal and takes top billing on everything from publications to patents to the glory that goes with them. Those in turn are crucial to getting more grants. It is self-perpetuating and self-limiting and over the past decade has increasingly stifled young investigators in particular because the percentage of grant applications that are funded by...the so-called pay line, is now below $10 \%$ and falling.

The first-generation model of research might work for conventional academic research. In fact it is acknowledged that the first-generation model might possibly be best suited for basic work that harnesses the idiosyncratic creativeness of individuals. For Saparito (2013:27) the "traditional researcher, sitting alone or with a couple of postdocs in a lab somewhere, working on that eureka moment, will always have a niche in this new eco-system [of "dream team research]". However, it is argued that threats to human health also extend to problems that can possibly threaten the lives of people on a global scale. For such threats, the dream team model is an improvement but requires a synthesis with a distributed knowledge and data methodology in order to meet these kinds of threats. For the purposes of solving problems such as the threat of global pandemics after they have emerged, a distributed problem solving methodology, or a secondgeneration R\&D methodology, may be required. The crowdsourcing model is a candidate for this mantle.

The use of crowdsourcing has already been considered in relation to its use in science and medicine (Torr-Brown, 2013). For Torr-Brown (2013:1):

With the advent of the Internet followed by advances in social media, data have become transparent as well as more plentiful and complex, creating significant challenges in analysis and interpretation for the scientific community. In parallel, the virtual environment has expanded the reach of science to include interested parties of all skill and knowledge levels. No longer is science the domain of experts. It is increasingly recognized that harnessing large virtual networks of human intelligence and man power can facilitate science, from funding through to execution. Crowdsourcing is an idea whose time has come, with signs of success in many areas relevant to medicine.

For Torr-Brown (2013:2), future "scientific progress is likely to occur through networks of human intelligence that can frame and solve difficult problems but are also supported by supercomputing capabilities". The constraints to funding faced by medical research make crowdsourcing a viable alternative (Torr-Brown, 2013:2). For Torr-Brown (2013:2), crowdsourcing is "the act of outsourcing tasks through an open call for participation to experts, skilled enthusiasts, or the general public to donate time, money, insights, or computing power to a particular framed problem". Crowdsourcing has been relatively successful to date as a model for solving these types of problems in science and medicine (Torr-Brown, 2013:2). In the area of distributed computing, home users are contributing to the collection and processing of radio signals in the scanning of signals from space, and the Folding@Home project uses over 160000 home computers to study protein folding associated with neurodegenerative diseases and cancer research (Torr-Brown, 2013:2). Academic medical research is now, belately, catching up with the increasing use of this methodology.

Research on crowdsourcing in medical journals is increasing; the first publication was in 2009, with three between 2009 and 2010, 10 in 2011, 24 in 2012 and 11 already published by March 2013 (Torr-Brown, 2013:2). Crowdsourcing has been applied to data collection; to clinical data collection, collecting data for personalized medicine and collecting genomics data (Torr-Brown, 2013). Crowdsourcing has also been applied to data analysis, as the human ability to analyse data qualitatively and in a way that incorporates contextual information while being able to contend with "ambiguity and imprecision extends our contextual advantages beyond computers alone" (Torr-Brown, 2013). Cancer research UK (CRUK) is another example of an organization that has resorted to crowdsourcing in order to identify cancer cells through this new phenomenon, termed citizen science (Torr-Brown, 2013). Quality control measures are designed into the system, which can identify reliable contributors (Torr-Brown, 2013). Problem solving using crowdsourcing has also been applied through the use of video games (Torr-Brown, 2013). According to Torr-Brown (2013:4):

Developers at the University of Washington in Seattle give players an image of a protein molecule along with video game-like tools for folding the molecule. In the game, the lower the amount of energy required to maintain the shape of the molecule falls, the closer the molecule is considered to be to its actual form in nature. Using the game, players have figured out the structure of a retroviral protease that is important for AIDS research, and have remodelled the molecule to 
increase its enzyme activity. The structure had previously been pursued by scientists for over a decade, but took the Foldlt players just three weeks to solve.

Interestingly, both scientists and the public seem to be incentivised to also participate in these kinds of projects independently of rewards (Torr-Brown, 2013).

Another application of crowdsourcing to medical research is in the area of fundraising, where ideas that might not clear the hurdles associated with the typical fund raising process can be funded (Torr-Brown, 2013). Crowdsourcing has also been applied to drug research and development; in finding applications for abandoned compounds, in clinical trials and in other applications (Torr-Brown, 2013). The successes of crowdsourcing achieved by Innovation Challenge and InnoCentive provide some degree of proof of concept that can have significant implications for the management of medical research (Torr-Brown, 2013). The profit motive seems to be compatible with the potential of crowdsourcing to solve problems (Torr-Brown, 2013:5):

One such collaboration, between GE's (General Electric's) Healthymagination and 4 leading venture capital firms, launched a 100 million dollar challenge to target breast cancer in September 2011 and in that two-month period almost 6000 people were engaged, with over 500 ideas submitted for improvements in diagnosis and treatment of cancer. Five winners were selected and received $\$ 100,000$ from GE to facilitate follow-up.

As a methodology, crowdsourcing seems to offer multidisciplinary problem solving as its primary advantage. Notwithstanding this potential, there exist certain challenges associated with its use. These challenges in medical R\&D mirror those found in other fields. The accuracy of data collected or analysed by nonexperts is still problematic (TorrBrown, 2013:5). Verification systems need to be developed and applied, perhaps with the recruiter of participants held accountable (Torr-Brown, 2013). Another challenge has been identified through the development of Wikipedia as a crowd-sourcing method of data collection; knowledge accepted seems to be biased toward accepted knowledge and it is "less inclined to publish information that contradicts that" (Torr-Brown, 2013:5). "The bias afforded by the crowd leads to an effective closing off to new interpretations, which tends ensure that common wisdom outweighs "expert" views" (TorrBrown, 2013:5). Crowdsourcing as a second-generation of R\&D might not be suited to basic research that requires idiosyncratic approaches. Conventional academic research might retain its place as the primary form of non-applied, or basic, knowledge creation. It is argued, however, that applied forms of knowledge creation such as second generation R\&D applications are uniquely suited to addressing extreme forms of problems. However, ethical issues also arise.

Ethical issues are also a problem with the application of crowdsourcing to personalised medicine; the questions of ownership of data and information feedback to respondents are examples of these issues (Torr-Brown, 2013:6). However, notwithstanding these challenges, the demand for more open source data seems to be driven by patients themselves (Torr-Brown, 2013). It has been suggested that an Institutional Review Board (IRB) may be necessary for health-related activities undertaken using the Internet (Torr-Brown, 2013:6). The application of crowdsourcing in health sciences, however, seems to be growing: Google searchers are now used to determine disease incidence, based on the assumption that searches about a disease are correlated with diagnoses (Torr-Brown, 2013:6). However, problems have also emerged; overestimations dominate which might need recalibration (Torr-Brown, 2013). Further research is needed into the ethical implications of medical uses of crowdsourcing.

A recommendation that arises from the above discussions is that a similar model to the InnoCentive model might be applied across nations. If the ongoing health budgets of all nations, for one year, that are allocated to addressing a particular problem (for example health costs associated with antibiotic resistance) were pooled, the cumulative cash incentive might be substantial. Because of the size of this incentive, it may be possible that such a problem (antibiotic resistance) could be solved in this manner. If the problem is solved, nations win because they then save this cost on an ongoing basis. The attempts to solve catastrophic problems such as AIDS, tuberculosis and malaria, associated as they are with under-resourced developing contexts, might benefit from the application of the principles derived from the successes of InnoCentive and other projects. Having presented the arguments made in this paper, and having made certain recommendations based on these arguments, the paper is now concluded.

\section{Conclusion}

This paper has offered the argument that non-probabilistic, or first-generation R\&D management systems, are unsuited to the management of certain types of catastrophic problems. The examples used in this paper to illustrate the argument are cases of bioevents in the form of pandemics where data is only typically available after the event has started. It was argued that the assumptions associated with first generation, or non-probabilistic, R\&D need to be revisited. It was argued that a proactive roll-out of a probabilistic, or distributed knowledge system is needed in order to prepare for these types of problems. 


\section{References}

Amin, Y., Dam, K. T., Nicola, T. J., Salama, S. R. and Yassine, K. L. (2006) Bio-Event Resource Management System (BRMS). Available at: http://www.sys.virginia.edu/sieds06/papers/FMorningSession6.1.pdf (Accessed 3 June 2013)

Armstrong, A. W., Harskamp, C. T., Cheeney, S., Wu, J. and Schupp, C. W. (2012) Power of crowdsourcing: novel methods of data collection in psoriasis and psoriatic arthritis. Journal of American Academic Dermatology, 67(6), 1273-1281.

BBC. (2013) WHO urges information sharing over novel coronavirus. Available at: http://www.bbc.co.uk/news/health-22649922 (Accessed 30 May 2013)

Billings, M. (1997) The Influenza Pandemic of 1918. Available at: http://virus.stanford.edu/uda/ (Accessed 30 May 2013)

Bradham, D. C. (2008). Crowdsourcing as a model for problem solving. An introduction and cases. Convergence: the international journal of research into new media technologies, 14(1), 75-90.

Burkle, F. 2006. Population-based Triage Management in Response to Surge-capacity Reqirements during a Large-scale Bioevent Disaster. Academic Emergency Medicine, 13, 1118-1129.

Callaghan, C.W. (2014a). R\&D Failure and Second Generation R\&D: New Potentialities. Mediterranean Journal of Social Sciences, 5(3), 11-24.

Callaghan, C.W. (2014b). Values and Research Productivity. Mediterranean Journal of Social Sciences, 5(1), 453-465.

Coase, R. H. (1937). The Nature of the Firm. Available at: http://purao.ist.psu.edu/532/Readings/Coase1937.pdf Accessed 8 June 2013.

Collier, N., Son, N. T. and Nguyen, N. M. (2011) OMG U got flu? Analysis of shared health messages for bio-surveillance. Journal of Biomedical Semantics, 2(Suppl.5), S9. http://www.ncbi.nlm.nih.gov/pmc/articles/PMC3239309/

Coldwell, D.A.L., and Callaghan, C.W. (2013). An empirical analysis of career subject majors on the basis of internal versus external factors. South African Journal of Economic and Management Sciences, 16(3), 244-257.

Collmann, J. and Robinson, A. (2011) Designing Ethical Practice in Biosurveillance. Infectious Disease Informatics and Biosurveillance. Available at: http://www.libreriauniverso.it/pdf/9781441968913.pdf (Accessed 3 June 2013)

Doloi, H. K. (2011). Understanding stakeholders' perspective of cost estimation in project management. International Journal of Project Management, 29(5), 622-636.

Eshel, B. (2013). Learning about Bacteria from Natural Information Processing. Annals of the New York Academy of Sciences, 1178(1), 78-90.

Grant, R. M. (1996). Toward a Knowledge-Based Theory of the Firm. Strategic Management Journal, 17, 109-122.

Halifax, J. (2013) Superbugs immune to antibiotics a threat to humans as big as terrorism or climate change. Available at: http://www.birminghammail.co.uk/lifestyle/health/superbugs-immune-antibiotics-bigger-threat-3410907 (Accessed 30 May 2013)

Howe, J. (2006) The Rise of Crowdsourcing. Wired Magazine, 14.06. Available at: http://sistemas-humano-computacionais.wdfiles.com /local--files/capitulo\%3Aredes-sociais/Howe_The_Rise_of_Crowdsourcing.pdf (Accessed 27 May 2013).

Kobayashi, T., Nakamori, Y. and Wierzbicki, A. P. (2007). Management of Technology in Academic Research. Studies in Computational Intelligence, 59, 353-369.

Lakhani, K. R. and Panetta, J. A. (2007). The principles of distributed innovation. Innovations: technology, governance, globalization, 2(3), 97-112.

Lakhani, K. R. and von Hippel, E. 2003. How open software works: "free" user-to-user assistance. Research Policy, 32: $923-943$.

Lakhani, K. R., and Wolf, R. G. (2005) Why Hackers Do What They Do: Understanding Motivation and Effort in Free/Open Source Software Projects. In Feller, J., Fitzgerald, B., Hissam, S., and Lakhani, K. R. (Eds). Perspectives on Free and Open Source Software. Available at: http://jpkc.hebtu.edu.cn/NR/rdonlyres/Sloan-School-of-Management/15-352Spring-2005/D2C127A9B712-4ACD-AA82-C57DE2844B8B/0/lakhaniwolf.pdf Accessed 9 June 2013

Maher, K. (2013) The Drugs Don't Work. Time Magazine. Available at: http://www.bbc.co.uk/news/health-22649922 (Accessed 30 May 2013).

Saparito, B. (2013). The Conspiracy to End Cancer. Time Magazine, April, 20-27.

Swan, M. (2012) Crowdsourced health research studies: an important emerging complements to clinical trials in the public health research ecosystem. Journal of Medical Internet Research, 14(2), e46.

Zap, C. (2013) New virus called 'threat to the entire world'. The Lookout. Available at: http://news.yahoo.com/blogs/lookout/virus-calledthreat-entire-world-152046513.html (Accessed 30 May 2013) 